\title{
Effects of free fatty acids on glucose transport and IRS-1-associated phosphatidylinositol 3-kinase activity
}

\author{
Alan Dresner, ${ }^{1}$ Didier Laurent, ${ }^{1}$ Melissa Marcucci, ${ }^{2}$ Margaret E. Griffin, ${ }^{1,2}$ Sylvie Dufour, ${ }^{1,2}$ \\ Gary W. Cline, ${ }^{1}$ Lori A. Slezak, ${ }^{3}$ Dana K. Andersen, ${ }^{3}$ Ripudaman S. Hundal, ${ }^{1}$ \\ Douglas L. Rothman, ${ }^{4}$ Kitt Falk Petersen, ${ }^{1}$ and Gerald I. Shulman ${ }^{1,2}$
}

${ }^{1}$ Department of Internal Medicine,

${ }^{2}$ The Howard Hughes Medical Institute,

${ }^{3}$ Department of Surgery, and

${ }^{4}$ Department of Diagnostic Radiology, Yale University School of Medicine, New Haven, Connecticut 06520-8020, USA

Address correspondence to: Gerald I. Shulman,Yale University School of Medicine, FMP 104, 333 Cedar Street, New Haven, Connecticut 06520-8020, USA. Phone: (203) 785-5447; Fax: (203)-785-6015; E-mail: gerald.shulman@yale.edu

Received for publication August 21, 1998, and accepted in revised form November 23, 1998.

To examine the mechanism by which free fatty acids (FFA) induce insulin resistance in human skeletal
muscle, glycogen, glucose-6-phosphate, and intracellular glucose concentrations were measured using
carbon-13 and phosphorous-31 nuclear magnetic resonance spectroscopy in seven healthy subjects
before and after a hyperinsulinemic-euglycemic clamp following a five-hour infusion of either
lipid/heparin or glycerol/heparin. IRS-1-associated phosphatidylinositol 3-kinase (PI 3-kinase) activi-
ty was also measured in muscle biopsy samples obtained from seven additional subjects before and after
an identical protocol. Rates of insulin stimulated whole-body glucose uptake. Glucose oxidation and
muscle glycogen synthesis were 50\%-60\% lower following the lipid infusion compared with the glycerol
infusion and were associated with a $~ 90 \%$ decrease in the increment in intramuscular glucose-6-phos-
phate concentration, implying diminished glucose transport or phosphorylation activity. To distin-
guish between these two possibilities, intracellular glucose concentration was measured and found to
be significantly lower in the lipid infusion studies, implying that glucose transport is the rate-control-
ling step. Insulin stimulation, during the glycerol infusion, resulted in a fourfold increase in PI 3-kinase
activity over basal that was abolished during the lipid infusion. Taken together, these data suggest that
increased concentrations of plasma FFA induce insulin resistance in humans through inhibition of glu-
cose transport activity; this may be a consequence of decreased IRS-1-associated PI 3-kinase activity.
J. Clin. Invest. 103:253-259 (1999).

\section{Introduction}

Increased plasma free fatty acid (FFA) concentrations are typically associated with many insulin-resistant states including obesity and type 2 diabetes mellitus (1-3). Furthermore, raising plasma FFA levels in healthy humans, by triglyceride/heparin infusions, can also acutely induce insulin resistance (4-11). Over thirty years ago, Randle et al. $(12,13)$ demonstrated that FFAs compete with glucose for oxidation in isolated rat heart and diaphragmatic muscle preparations, and they speculated that increased fat oxidation may cause the insulin resistance associated with diabetes and obesity. They proposed that increased FFA oxidation leads to an increase in the intramitochondrial acetyl-coenzyme A (acetyl-CoA) and reduced/oxidized nicotinamide adenine dinucleotide $\left(\mathrm{NADH} / \mathrm{NAD}^{+}\right.$) ratios, resulting in inactivation of pyruvate dehydrogenase activity. The consequent increase in intracellular citrate concentration causes inhibition of phosphofructokinase resulting in an increase in glucose-6-phosphate levels. The elevated glucose-6-phosphate levels would inhibit hexokinase II activity and then lead to decreased glucose uptake. However, recent studies by our group (14) and others $(15,16)$ have called this mechanism into question. Boden and coworkers have shown that a reduction in carbohy- drate oxidation was responsible for only one-third of the fatty acid-dependent decrease in glucose uptake, while impaired non-oxidative glucose metabolism accounted for the remainder (16). These workers suggested that two different defects might contribute to the impairment in nonoxidative glucose metabolism. At FFA concentrations of $\sim 0.75 \mathrm{mM}$, they found an increase in glucose- 6 phosphate concentrations in muscle biopsies, suggesting an inhibitory effect of FFA on glycogen synthase activity, whereas at lower FFA concentrations $(\sim 0.50$ $\mathrm{mM}$ ) they observed no difference in intramuscular glucose-6-phosphate concentration. In contrast, using carbon-13/phosphorous-31 nuclear magnetic resonance (NMR) spectroscopy under increased plasma FFA concentrations $(\sim 1.8 \mathrm{mM})$, we observed a decrease in intramuscular glucose-6-phosphate concentration associated with a $50 \%$ reduction in insulin-stimulated muscle glycogen synthesis (14). These data suggest that acute elevations in plasma FFA levels in humans cause insulin resistance by initial inhibition of glucose transport and/or phosphorylation activity that is concurrently followed by a reduction in the rate of both muscle glycogen synthesis and glucose oxidation. Because glucose-6phosphate (and not intracellular glucose) concentration was measured, it was not possible to distinguish between 
an FFA-induced reduction in glucose transport activity or an FFA-induced reduction in glucose phosphorylation (hexokinase II) activity.

The mechanisms that may underlie these FFA-induced changes in glucose transport/ phosphorylation activity are unknown but may include effects on the insulin signaling cascade. The effect of elevated FFA levels on insulin binding and post-receptor insulin-mediated signaling is presently not well understood, and contradictory data have been found (17-19). The conflicting results seen in these in vitro studies may be due to differences in cell types or conditions of the incubations. In the only

$a$

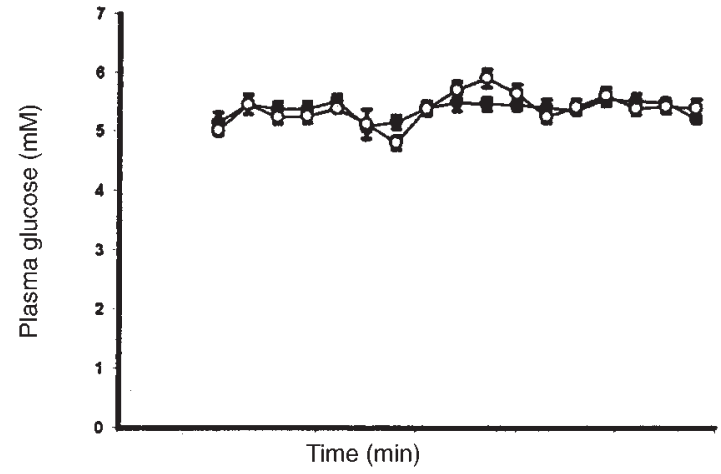

$b$

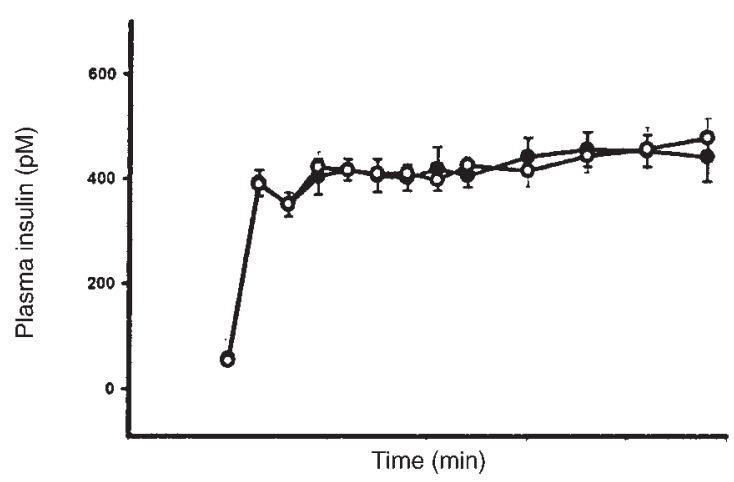

$c$

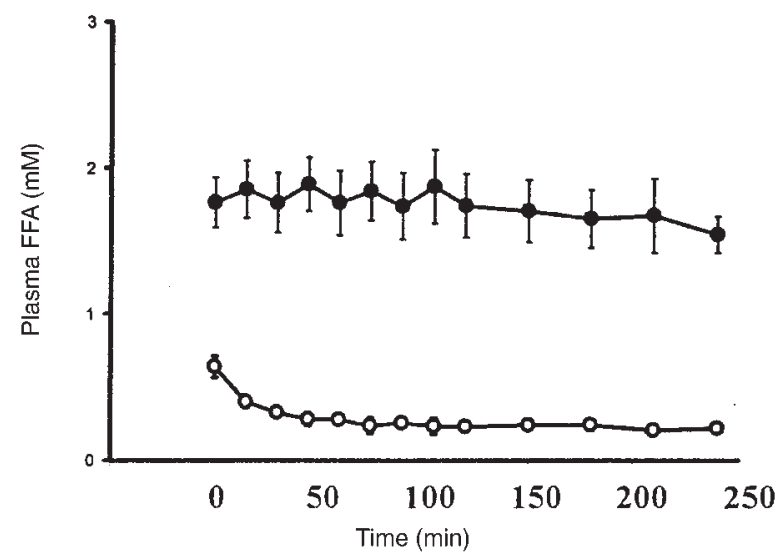

Figure 1

Plasma concentrations of glucose $(\boldsymbol{a})$, insulin $(\boldsymbol{b})$, and FFAs $(\boldsymbol{c})$ during the hyperinsulinemic-euglycemic clamp following 5 h of glycerol (open circles) or lipid (solid circles) infusion. FFA, free fatty acid. human study to date, Gumbiner et al. (20) examined insulin receptor autophosphorylation in muscle biopsies taken before and after a lipid/heparin infusion and found no reduction in insulin receptor autophosphorylation.

The experiments performed in this study were designed (a) to examine whether elevations in plasma FFA concentrations cause a reduction in glucose transport activity or hexokinase II activity by measuring intracellular glucose concentrations using a novel carbon-13 NMR approach, and $(b)$ to examine whether insulin-stimulated IRS-1-associated phosphatidylinositol (PI) 3-kinase activity in muscle is affected by elevations in plasma FFA concentrations.

\section{Methods}

Subjects. Fourteen healthy volunteers (thirteen males, one female; age range: $18-33$ years; body wt: $75.8 \pm 2.9 \mathrm{~kg}$; body mass index: $23.8 \pm 0.5 \mathrm{~kg} / \mathrm{m}^{2}$ ) without family history of diabetes mellitus, dyslipidemia, or bleeding disorders were put on an isocaloric diet (30 kcal per kg/day; carbohydrate/protein/fat: $60 \% / 20 \% / 20 \%$ ) for 3 days. They were admitted to the Yale/New Haven Hospital General Clinical Research Center the evening before the study and fasted for $12 \mathrm{~h}$ before participating in either an NMR or muscle biopsy study. On the morning of the study, Teflon catheters were inserted in the antecubital veins of the right and left arm for blood sampling and glucose/lipid/hormone infusions, respectively. Each subject was studied twice (basal plasma FFA concentrations [glycerol/heparin infusion] or increased plasma FFA concentrations [lipid/heparin infusion]) in either an NMR protocol $(n=7)$ or muscle biopsy protocol $(n=7)$. Informed and written consent was obtained from each volunteer. All protocols were approved by the Yale University Human Investigation Committee.

Lipid/glycerol infusions. To examine the effect of increased plasma FFA concentrations on insulin-stimulated muscle glucose metabolism, plasma concentrations of FFAs were increased by intravenous infusion of a triglyceride emulsion $(1.5 \mathrm{ml} / \mathrm{min}$; Liposyn II, Abbott Laboratories, North Chicago, Illinois, USA) combined with a prime (200 IU)-continuous ( $0.2 \mathrm{IU}$ per $\mathrm{kg} / \mathrm{min}$ ) infusion of heparin to activate lipoprotein lipase. During the control experiments, glycerol $(0.7 \mathrm{mg}$ per $\mathrm{kg} / \mathrm{min})$ was substituted for the lipid infusion. Subjects were randomized with respect to the order in which they received the two infusions. Studies were performed within 2-4 weeks of each other.

Hyperinsulinemic-englycemic clampstudies. After 5 h of the lipid or glycerol infusion, a hyperinsulinemic-euglycemic clamp using [1${ }^{13} \mathrm{C}$ ]glucose (20g/dl, 40\%-60\% carbon- 13 enriched; Cambridge Isotopes, Cambridge, Massachusetts, USA) was begun ( $t=0 \mathrm{~min}-$ utes). The subjects were also infused with $\left[1-{ }^{13} \mathrm{C}\right]$ mannitol $(10 \mathrm{~g} / \mathrm{dl}, 99 \%$ carbon-13 enriched; Cambridge Isotopes) (prime [3.8 g]-continuous $[1.4 \mathrm{~g} / \mathrm{min}]$ ) to assess intracellular glucose concentration, as previously described (21). Insulin (HumulinRegular; Eli Lilly and Co., Indianapolis, Indiana, USA) was administered as a prime $(18 \mathrm{mU} / \mathrm{kg})$-continuous $(1 \mathrm{mU}$ per $\mathrm{kg} / \mathrm{min}$ ) infusion to create conditions of hyperinsulinemia ( 400 $\mathrm{pM}$ ) for $240 \mathrm{~min}$. Plasma concentrations of glucose were maintained at $\sim 5 \mathrm{mM}$ by varying the infusion rate of the $\left[1-{ }^{13} \mathrm{C}\right] \mathrm{glu}-$ cose. Both the lipid and glycerol infusions were continued throughout the clamp for both the NMR and biopsy studies.

NMR studies. In vivo carbon-13/phosphorous-31 NMR spectroscopy was performed on the right calf muscle to assess glycogen, glucose-6-phosphate, and intracellular glucose concentrations. Subjects remained in the supine position inside a $2.1 \mathrm{~T}$ Biospec NMR spectrometer system (Bruker Instruments Inc., Billerica, Massachusetts, USA), and phosphorous-31 NMR spectra were acquired (22) to measure intracellular glucose-6-phosphate concentration before the clamp ( $t=-40$ to $0 \mathrm{~min}$ ) and from 20 to 60 min during the clamp. Carbon-13 NMR spectra for glycogen concentrations were acquired before the clamp $(t=$ 
-60 to $-40 \mathrm{~min}$ ) and from 120 to $180 \mathrm{~min}$ during the clamp to measure rates of muscle glycogen synthesis as previously described $(23,24)$. Intracellular glucose concentrations were measured by carbon-13 NMR spectroscopy from 180 to $240 \mathrm{~min}$ as described previously (21). The radio frequency (RF) coil assembly consisted of two circular hydrogen- 1 coil loops (13-cm diameter each) arranged spatially to generate a quadrature field and an $8.5-\mathrm{cm}$ diameter circular surface coil for carbon- 13 detection (25). Unlocalized shimming was performed using FASTERMAP (26). The $\mathrm{B}_{2}$ field was calibrated using a stimulated echo $y$ column profile that generated a $180^{\circ}$ null at the gradient isocenter. Heteronuclear nuclear Overhauser enhancement was achieved by a train of inversion pulses to the hydrogen-1 nuclei during the relaxation delay. A numerically optimized adiabatic half-passage pulse was used for carbon-13 excitation (27) followed by WALTZ-16 hydrogen-1 decoupling. The repetition rate was $2 \mathrm{sec}$ per scan. The creatine $(\mathrm{Cr})$ signal observed in the carbon-13 NMR spectrum is from both creatine and phosphocreatine (PCr). Assuming the total creatine ( $\mathrm{Cr}+$ $\mathrm{PCr}$ ) signal is compartmentalized to the same intracellular muscle space and is natural abundance carbon-13, we calculate the extracellular to intracellular volumes from the in vivo NMR signal intensity of $\mathrm{Cr}^{\text {total }}$ to mannitol as described previously (21).

Muscle biopsy studies. After the subjects were supine and resting quietly for $60 \mathrm{~min}$, the right vastus lateralis muscle was sterilely prepared with betadine, and $1 \%$ lidocaine was given subcutaneously. A 2-cm incision was made using a scalpel, and a 5-mm Bergstrom biopsy cannula (Warsaw, Indiana, USA) was used to perform a baseline punch muscle biopsy. The muscle tissue was blotted and snap frozen in liquid nitrogen. After this, a 5-h infusion of lipid/heparin or glycerol/heparin was given. At the fifth hour, while the infusions continued, a hyperinsulinemiceuglycemic clamp was begun as described above. After $30 \mathrm{~min}$ of hyperinsulinemia, a repeat punch muscle biopsy was performed. All samples were stored at $-80^{\circ} \mathrm{C}$ until assay.

Materials. Phosphatidylinositol was purchased from Avanti Polar Lipids (Arlington, Alabama, USA) and phosphatidylinositol 4-phosphate from Sigma Chemical Co. (St. Louis, Missouri, USA). Reagents for the detection of Western blots by enhanced chemiluminescence, rainbow-colored molecular weight markers for SDS-PAGE, and $\left[\gamma^{-32} \mathrm{P}\right]$ ATP $(6000 \mathrm{Ci} / \mathrm{mmol})$ were purchased from Amersham Life Sciences Inc. (Arlington Heights, Illinois, USA). Protein GPLUS/Protein A-Agarose immunoprecipitation reagent was purchased from Calbiochem (Cambridge, Massachusetts, USA). Antibodies against IRS-1CT (rabbit polyclonal) and PI 3-kinase (p85 subunit, rabbit polyclonal) were a gift from M.F. White (Joslin Diabetes Center, Boston, Massachusetts, USA). Horseradish peroxidase-labeled anti-mouse and anti-rabbit secondary antibodies were obtained from Rockland Inc. (Gilbertsville, Pennsylvania, USA).

Muscle preparation for insulin signaling studies. Muscle extracts were made from the frozen specimens. Muscles were first powdered under liquid nitrogen with a mortar and pestle and then homogenized in ice-cold buffer (20 mM HEPES, pH 7.4, $50 \mathrm{mM} \beta$-glycerol phosphate, $2 \mathrm{mM}$ DTT, $1 \mathrm{mM} \mathrm{Na}_{3} \mathrm{VO}_{4}, 2 \mathrm{mM}$ EDTA, $1 \mathrm{mM}$ PMSF, 1\% Triton X-100, 10\% glycerol, $10 \mu \mathrm{M}$ Leupeptin, $3 \mathrm{mM}$ Benzamidine, $5 \mu \mathrm{M}$ Pepstatin A, $10 \mu \mathrm{g} / \mathrm{ml}$ Aprotinin, $200 \mu \mathrm{g} / \mathrm{ml}$ soybean trypsin inhibitor). The homogenate was solubilized on a rotating mixer at $4^{\circ} \mathrm{C}$ for $30-60 \mathrm{~min}$ and centrifuged at 15,000 rpm for $60 \mathrm{~min}$ in a $70.1 \mathrm{Ti}$ rotor in a Beckman Ultracentrifuge (Fullerton, California, USA). The supernatant was collected and assayed for total protein content using the Bio-Rad Laboratories Inc. (Hercules, California, USA) protein assay kit.

PI 3-kinase activity measurements. IRS-1-associated PI 3-kinase activity was measured in immunoprecipitates obtained with antibodies to IRS- 1 as described previously, with some modifications $(28,29)$. A 1-mg aliquot of muscle extract (total protein) was added to the immune complex composed of protein $A / G$ agarose

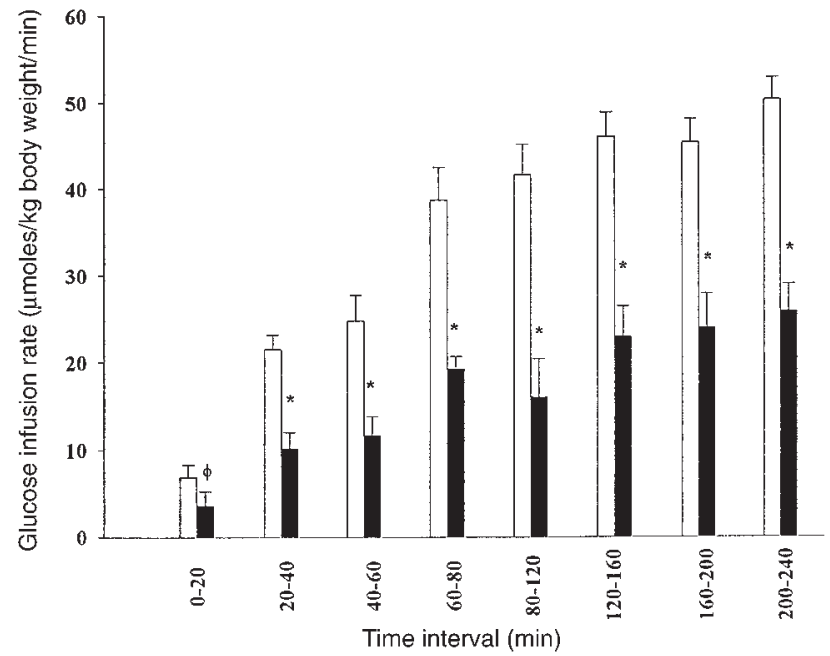

Figure 2

Mean rates of glucose infusion during the hyperinsulinemic-euglycemic clamp following $5 \mathrm{~h}$ of glycerol (open bar) or lipid (solid bar) infusion.

and anti-IRS- 1 antibody and allowed to incubate overnight. The immunocomplexes were collected by centrifugation, washed twice with PBS containing $1 \% \mathrm{NP}-40 / 100 \mu \mathrm{M} \mathrm{Na}_{3} \mathrm{VO}_{4}$, twice with $100 \mathrm{mM}$ Tris ( $\mathrm{pH} 7.5$ ) containing $500 \mathrm{mM} \mathrm{LiCl}_{2} / 100 \mu \mathrm{M}$ $\mathrm{Na}_{3} \mathrm{VO}_{4}$, and twice with Tris ( $\mathrm{pH} 7.5$ ) containing $100 \mathrm{mM} \mathrm{NaCl}$, $1 \mathrm{mM}$ EDTA/ $100 \mu \mathrm{M} \mathrm{Na}_{3} \mathrm{VO}_{4}$. The pellets were then resuspended in $50 \mu \mathrm{l}$ of the final wash buffer and $12 \mathrm{mM} \mathrm{MgCl}_{2}$, and $20 \mu \mathrm{g}$ phosphatidylinositol was added. To start the PI 3-kinase reaction, $10 \mu \mathrm{l}$ of $440 \mu \mathrm{M}$ ATP containing $30 \mu \mathrm{Ci}$ [ $\left.{ }^{32} \mathrm{P}\right] \mathrm{ATP}$ was added to the pellets at room temperature. After $10 \mathrm{~min}, 20 \mu \mathrm{l}$ of $8 \mathrm{M}$ HCL was added to stop the reaction, followed by $160 \mu \mathrm{l}$ of $\mathrm{CHCl}_{3} / \mathrm{CH}_{3} \mathrm{OHOH}(1: 1)$. The phases were separated by centrifu-
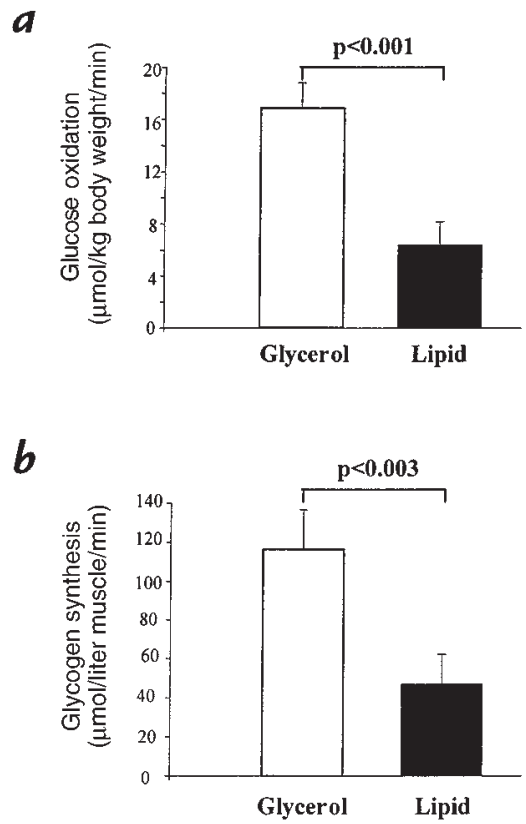

Figure 3

(a) Mean rates of glucose oxidation assessed by indirect calorimetry (measured from $t=95-115 \mathrm{~min}$ ). (b) Mean rates of muscle glycogen synthesis assessed by carbon-13 NMR (measured from $t=120$ to $180 \mathrm{~min}$ ) during the hyperinsulinemic-euglycemic clamp following $5 \mathrm{~h}$ of glycerol or lipid infusion. 


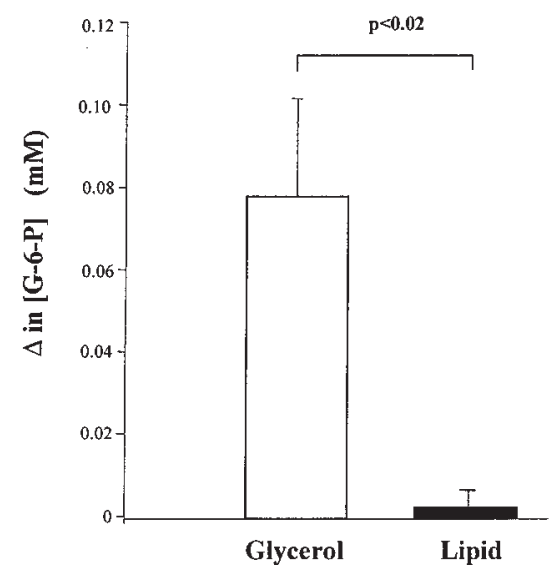

Figure 4

Increment in intracellular [G-6-P] obtained from 20 to 60 min after beginning the hyperinsulinemic-euglycemic clamp following $5 \mathrm{~h}$ of glycerol or lipid infusion. [G-6-P], glucose-6-phosphate concentration.

gation, and $50 \mu \mathrm{l}$ of the lower organic phase was spotted onto a glass-backed silicon TLC plate. The lipids were resolved by TLC in $\mathrm{CH}_{3} \mathrm{OHOH} / \mathrm{CHCl}_{3} / \mathrm{H}_{2} \mathrm{O} / \mathrm{NH}_{4} \mathrm{OH}(60: 47: 11.3: 2)$ and visualized by autoradiography. The radioactivity that comigrated with the PI 4-phosphate standard was scraped from the TLC plate and quantified by scintillation counting.

Respiratory exchange measurements. During the biopsy studies continuous indirect calorimetry was performed from 95 to 115 min during the hyperinsulinemic-euglycemic clamp to determine rates of whole-body glucose oxidation. From these data and from the amount of nitrogen excreted in the urine, rates of nonoxidative metabolism were calculated.

Analytical procedures. Plasma glucose concentrations were measured by the glucose oxidase method (Glucose Analyzer II; Beckman Instruments Inc., Fullerton, California, USA). Plasma concentrations of FFAs were determined using microfluorimetric methods. Plasma immunoreactive insulin was determined by a double antibody RIA (Diagnostic Systems Laboratories Inc., Webster, Texas, USA). Plasma $\left[1-{ }^{13} \mathrm{C}\right] \mathrm{glu}-$

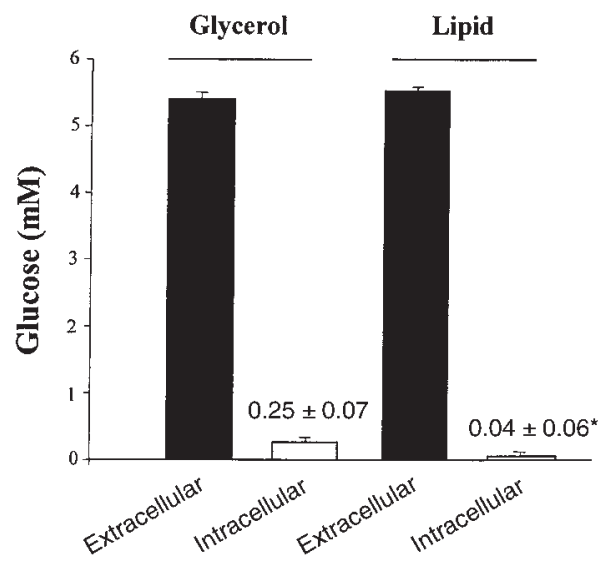

Figure 5

Mean intracellular glucose concentration (assessed by carbon-13 NMR) and mean extracellular (plasma) glucose concentration obtained from 120 to $240 \mathrm{~min}$ during the hyperinsulinemic-euglycemic clamp following $5 \mathrm{~h}$ of glycerol or lipid infusion. ${ }^{*} P=0.04$ versus intracellular glucose concentration during glycerol infusion. cose and mannitol (as acetate derivatives) atom percent excesses were measured using gas chromatography-mass spectrometry with a Hewlett-Packard (Palo Alto, California, USA) 5890 gas chromatograph (HP-1 capillary column, 12$\mathrm{m} \times 0.2-\mathrm{mm} \times 0.33-\mathrm{mm}$ film thickness) interfaced to a Hewlett-Packard 5971 MSD (methane chemical ionization) $(21,23)$

\section{Calculations and data analyses}

Increments in muscle glycogen concentration were determined from the change in $\left[1^{-13} \mathrm{C}\right]$ glycogen concentration and the plasma [1${ }^{13} \mathrm{C} 7$ glucose atom percent excess as described previously (24). Rates of glycogen synthesis were then calculated from the slope of the least-square linear fit to the glycogen concentration curve during the given time periods as described previously (24). The intracellular glucose concentration was calculated as described previously (21). All data are presented as mean \pm SEM. Statistical comparisons between control and lipid infusion experiments were performed by using the paired Student's $t$ test, except for the PI 3-kinase data, which were analyzed using analysis of variance followed by the Student-Newman Keuls post-hoc test.

Hypothetical intracellular glucose concentration resulting from reduced hexokinase flux with normal glucose transporter kinetics. We can simplify the metabolic steps regulating glycogen synthesis flux in muscle during steady state as: $\Delta\left[\mathrm{Glc}_{\mathrm{in}}\right] / \Delta t=V_{1}-V_{-1}-V_{\mathrm{HK}}$ $=0$, where $\Delta\left[\mathrm{Glc}_{\mathrm{in}}\right] / \Delta t$ is the change in the intracellular glucose concentration per change in time, $V_{1}$ is the rate of glucose transport influx into the cell, $V_{-1}$ is the rate of glucose efflux from the cell, and $V_{\mathrm{HK}}$ is the rate of hexokinase flux. Assuming MichaelisMenten kinetics yields: $V_{1}=V_{1}{ }^{\max }\left[\mathrm{Glc}_{\mathrm{ex}}\right] /\left(K_{\mathrm{m} 1}+\left[\mathrm{Glc}_{\mathrm{ex}}\right]\right)$ and $V_{-1}=$ $V_{-1} \max \left[\mathrm{Glc}_{\mathrm{in}}\right] /\left(K_{\mathrm{m}-1}+\left[\mathrm{Glc}_{\mathrm{in}}\right]\right)$. If we assume (a) symmetrical transport of glucose by Glut4 $\left(V_{1}{ }^{\max }=V_{-1}{ }^{\max }, K_{\mathrm{m} 1}=K_{\mathrm{m}-1}\right),(b)$ a $K_{\mathrm{m}}$ for Glut 4 of $5 \mathrm{mM}(37)$, and (c) that $V_{\mathrm{HK}}$ is approximately equal to the glycogen synthetic rate as measured in the glycerol infusion studies ( $\sim .10 \mathrm{mmol}$ per liter muscle/min), then given an extracellular glucose concentration of $5 \mathrm{mM}$ and an intracellular glucose concentration of $0.1 \mathrm{mM}$, substituting into equation 1 yields: $V_{1}^{\max } \quad\left[\mathrm{Glc}_{\mathrm{ex}}\right] /\left(K_{\mathrm{m} 1}+\left[\mathrm{Glc}_{\mathrm{ex}}\right]\right)-V_{-1} \max$ $\left[\mathrm{Glc}_{\mathrm{in}}\right] /\left(K_{\mathrm{m}-1}+\left[\mathrm{Glc}_{\mathrm{in}}\right]\right) \approx V_{\text {glycogen synthetic rate }}$ and $V_{1} \max [5 /(5+5)]-$ $V_{-1} \max [0.1 /(5+0.1)]=0.1 \mathrm{mmol}$ per liter muscle $\left./ \mathrm{min}\right)$ and $V_{1} \max$ $=0.21 \mathrm{mmol}$ per liter muscle $/ \mathrm{min}$. Assuming $V_{\mathrm{HK}}$ is decreased exclusively by FFA and that it is approximately equal to the glycogen synthetic rate in the lipid-infused subjects $(-0.05$ $\mathrm{mmol}$ per liter muscle/min) then repeating this calculation and substituting $V_{1} \max =0.21 \mathrm{mmol}$ per liter muscle $/ \mathrm{min}$ yields: 0.21 $\left.[5 /(5+5)]-0.21\left[\mathrm{G}_{\text {in }}\right] /\left(\left[\mathrm{G}_{\text {in }}\right]+5\right)\right]=0.05,\left[\mathrm{G}_{\text {in }}\right]=1.8 \mathrm{mM}$. This value is more than 40 times higher than that measured in the lipid-infused subjects.

\section{Results}

During the hyperinsulinemic-euglycemic clamps, plasma glucose concentrations remained constant $(\sim 5 \mathrm{mM})$ compared with the basal period in both the glycerol and lipid infusion studies (Fig. 1a). In both studies, plasma insulin concentrations increased to $\sim 400 \mathrm{pM}$ almost immediately after the clamp was begun and remained at that level throughout the clamp (Fig. 1b). In the glycerol infusion study, the plasma FFAs remained at the same levels after the five-hour glycerol/heparin infusions $(\sim 0.5$ $\mathrm{mM}$ ) and decreased to $\sim 0.1 \mathrm{mM}$ once the hyperinsulinemic-euglycemic clamp was started (Fig. 1c). During the lipid infusion, the plasma FFA concentrations increased to $\sim 1.8 \mathrm{mM}$ and remained at this level throughout the clamp (Fig. 1c). These plasma concentrations of FFA are similar to what we have reported previously (14), but 
higher than those reported by Boden et al. using a similar protocol (15). It is possible that these differences are due to some post-collection lipolysis in the present studies. However, to the extent that this occurred, plasma FFA concentrations would be overestimated and any observed effects of FFA on insulin-mediated glucose metabolism would be underestimated.

During the hyperinsulinemic-euglycemic clamp, whole-body glucose metabolism, as reflected by the mean glucose infusion rate, was $\sim 50 \%$ lower in the lipid infusion study as compared with the glycerol infusion study from the very beginning of the clamp (Fig. 2). It was also associated with $\sim 60 \%$ reduction in the rate of whole-body glucose oxidation (Fig. 3).

Carbon-13 NMR muscle glycogen measurements. Muscle glycogen concentrations were similar following five hours of the lipid $(66 \pm 2 \mathrm{mM})$ or glycerol $(63 \pm 4 \mathrm{mM})$ infusion. The insulin-stimulated rate of muscle glycogen synthesis was reduced by $\sim 60 \%$ in the lipid-infused group compared to the glycerol-infused group (Fig. 3).

Phosphorous-31 NMR muscle glucose-6-phosphate measurements. Glucose-6-phosphate concentration values before the start of the hyperinsulinemic-euglycemic clamps were $0.11 \pm 0.01$ and $0.12 \pm 0.01 \mathrm{mM}$ in the glycerol- and lipid-infused subjects, respectively. Once the hyperinsulinemic-euglycemic clamp was begun, there was an $\sim 0.080 \mathrm{mM}$ increase in intramuscular glucose-6-phosphate from 20 to 60 minutes into the clamp. In contrast, the lipid infusion protocol resulted in a $\sim 90 \%$ reduction in the insulin-stimulated increment in intracellular glucose-6-phosphate concentration compared with the glycerol-infused study during that same interval (Fig. 4).

Intracellular glucose concentration. Raising plasma FFAs resulted in a significant reduction in the intracellular glucose concentration in the lipid-infused group $(0.04 \pm$ $0.06)$ compared with the glycerol-infused group $(0.25 \pm$ $0.07, P=0.04)$. In both cases, there was over a 20 -fold concentration gradient between intracellular and extracellular glucose concentrations (Fig. 5).

IRS-1-associated PI 3-kinase activity. Following insulin stimulation, IRS-1-associated PI 3-kinase activity, assessed 30 minutes into the hyperinsulinemic-euglycemic clamp, increased fourfold over basal activity in the glycerol infusion studies ( $400 \pm 120 \%$ of basal, $P<0.01$; Fig. 6 ). In contrast, during the lipid infusion studies, there was a $>90 \%$ blunting in the insulin-stimulated IRS-1-associated PI 3kinase activity compared with the glycerol infusion studies, and there was no detectable increase in activity compared with the basal state (112 $\pm 13 \%$ of basal).

\section{Discussion}

In contrast to previous studies (14-16), in which the lipid infusion was started at the beginning of the hyperinsulinemic-euglycemic clamp, in the present study the lipid infusion was begun five hours prior to the start of the hyperinsulinemic-euglycemic clamp. Using this protocol we observed a $\sim 50 \%$ reduction in the rates of insulin-stimulated whole-body glucose metabolism that was present from the very beginning of the hyperinsulinemic-euglycemic clamp, and a $\sim 50 \%$ reduction in the rates of muscle glycogen synthesis and glucose oxidation during the lipid infusion studies. This reduction in insulin-stimulated muscle glucose metabolism was associated with a $>90 \%$ reduction in the insulin-stimulated increase in glucose-6-phosphate concentration. Taken together these data suggest that elevated plasma FFA concentrations inhibit insulin activation of glucose transport/phosphorylation activity and are contrary to the mechanisms proposed by Randle et al. $(12,13)$ and Boden et al. (for FFA concentrations $\geq 0.75 \mathrm{mM}$ ) (16), which both predict an increase in intramuscular glucose6-phosphate concentrations as a result of inhibitory effects of FFA on phosphofructokinase activity (via an increase in intracellular citrate concentration) or glycogen synthase activity, respectively. These data, however, are consistent with our previous results (14) and suggest that FFA interferes with insulin-stimulated muscle glucose metabolism via a different mechanism. While a previous study (30) failed to demonstrate an effect of a 2.5hour preinfusion of lipid/heparin on insulin-stimulated glucose metabolism, previous data $(14,16)$ suggests that a preinfusion of at least three hours is required to see this effect. Furthermore, these workers studied only type 2 diabetic subjects with this protocol. It is therefore likely that they were unable to observe any lipid-induced changes in insulin-stimulated muscle glucose metabolism, because these subjects were already insulin resistant. This is consistent with the hypothesis that FFA plays an important role in causing insulin resistance in patients with type 2 diabetes because little or no additive effect of further elevations in plasma FFA on insulinstimulated glucose metabolism would be predicted.

To distinguish between FFA inhibition of glucose transport activity and FFA inhibition of hexokinase II activity we measured intracellular concentrations of glucose in muscle using a novel carbon-13 NMR method that was recently validated in an animal model (21). Because intracellular glucose is an intermediate between glucose transport and hexokinase II, its concentration will reflect the relative activities of these two steps. If a decrease in hexokinase activity was responsible for the lower rate of insulin-stimulated muscle glycogen synthesis intracellular glucose concentrations should be

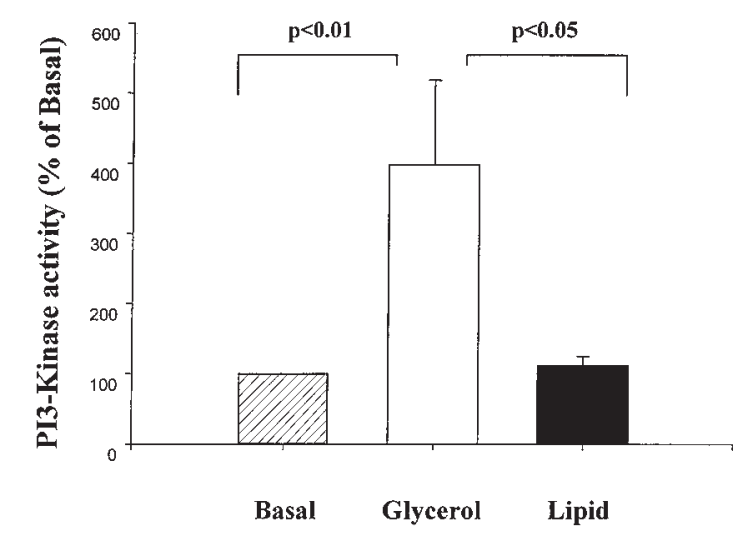

Figure 6

IRS-1-associated PI 3-kinase activity in muscle biopsies obtained before the glycerol/lipid infusions (basal) and after $30 \mathrm{~min}$ of the hyperinsulinemic-euglycemic clamp following $5 \mathrm{~h}$ of glycerol or lipid infusion. PI, phosphatidylinositol. 
$\geq 1.8 \mathrm{mM}$ (see Methods). However, if the impairment was at the level of glucose transport there should be either no difference or a decrease in the intracellular glucose concentration. We found that elevated plasma FFA concentrations caused a significant reduction in the intracellular glucose concentration in the lipid infusion studies compared with the glycerol infusion studies. These data imply that the rate-controlling step for FFA-induced insulin resistance in humans is glucose transport and offers further evidence against the Randle mechanism, which predicts an increase in both intracellular glucose6-phosphate and glucose concentrations.

This reduced glucose transport activity could be the result of FFA effects on the Glut4 transporter directly (i.e., alteration in Glut4 trafficking, Glut4 budding, Glut4 fusion, Glut4 activity, etc.) (31), or it could result from FFA-induced alterations in upstream insulin signaling events resulting in decreased Glut4 translocation to the plasma membrane. To further explore the latter possibility, we examined IRS-1-associated PI 3-kinase activity in muscle biopsy samples using the identical lipid infusion protocol. We found that similar elevations in plasma FFA levels abolished insulin-stimulated IRS-1-associated PI 3-kinase activity compared with a fourfold stimulation observed in the glycerol infusion studies. This work demonstrates for the first time in vivo that FFA-induced insulin resistance, as reflected by changes in intramuscular glucose-6-phosphate concentration, occurred in temporal relationship with alterations in insulin-stimulated PI 3-kinase activity - an important component of the insulin signaling pathway leading to activation of glucose transport activity in skeletal muscle $(32,33)$.

The reduced PI 3-kinase activity may be due to a direct effect of intracellular FFA (or some FFA metabolite) on PI 3-kinase and/or secondary to alterations in upstream insulin signaling events. An attractive hypothesis is that elevated plasma FFA levels leads to accumulation of intracellular fatty acyl CoAs; these then activate a serine kinase (possibly protein kinase $\mathrm{C} \theta$ ), leading to phosphorylation of serine sites on IRS-1 and/or the insulin receptor, which reduces IRS-1-associated PI 3-kinase activity (34). In support of the latter possibility, muscle strips from insulin-resistant obese subjects showed blunted insulin-stimulated PI 3-kinase activity associated with reduced insulin-stimulated insulin receptor and IRS-1 tyrosine phosphorylation (29). Similarly, Björnholm et al. (35) found reduced insulin-stimulated IRS-1 phosphorylation associated with reduced PI 3-kinase activity in muscle strips taken from subjects with type 2 diabetes suggesting a defect in the signaling pathway upstream of PI 3-kinase. More recently, Anai et al. (36) found lower insulin-stimulated PI 3-kinase activity in the Zucker fatty rat associated with relatively mild reductions in IRS- 1 and IRS-2 phosphorylation. However, in contrast to the present study, none of these studies were able to determine whether or not these alterations in insulin signaling were primary or secondary to the insulin resistance. In the only human study of the effect of increased plasma FFA concentrations on the insulin signaling pathway, Gumbiner et al. (20) found no change in insulin binding or insulin receptor tyrosine kinase in skeletal muscle biopsies taken after a lipid/heparin infusion when compared with a glyc- erol infusion; however, IRS-1, IRS-2, and PI 3-kinase proteins were not examined.

In conclusion, we found that elevations in plasma free fatty acid concentration cause insulin resistance in human skeletal muscle by reducing insulin-stimulated glucose transport activity, and this resistance appears to be a consequence of altered insulin signaling through IRS-1-associated PI 3-kinase. This mechanism may play an important role in causing the insulin resistance associated with obesity and type 2 diabetes.

\section{Acknowledgments}

We thank D. D'Eugenio, L. Burden, V. Walton, S. Vogel, and F. Rife for technical assistance, and we also thank the staff of the Yale/New Haven Hospital General Clinical Research Center. This work was supported by grants from the United States Public Health Service (RO1 DK-49230, P30 DK-45735, P60 AG-10469, and MO1 RR-00125) and by an unrestricted grant from BristolMyers Squibb. K.F. Petersen was supported by a Clinical Associate Physician Award from the National Institutes of Health (PA-9030). M. Griffin was supported by a Postgraduate Travelling Scholarship from the University of Dublin, Dublin, Ireland. G.I. Shulman is an investigator of the Howard Hughes Medical Institute.

1. Reaven, G.M., Hollenbeck, C., Jeng, C.-Y., Wu, M.S., and Chen, Y.-D. 1988. Measurement of plasma glucose, free fatty acid, lactate, and insulin for 24h in patients with NIDDM. Diabetes. 37:1020-1024.

2. Frayne, K.N. 1993. Insulin resistance and lipid metabolism. Curr. Opin. Lipidol.4:197-204.

3. Steiner, G., Morita, S., and Vranic, M. 1980. Resistance to insulin but not to glucagon in lean human hypertriglyceridemics. Diabetes. 29:899-905.

4. Thiebaud, D., et al. 1982. Effect of long chain triglyceride infusion on glucose metabolism in man. Metab. Clin. Exp. 31:1128-1136.

5. Ferrannini, E., Barrett, E.J., Bevilacqua, S., and DeFronzo, R.A. 1983. Effect of fatty acids on glucose production and utilization in man. J. Clin. Invest. 72:1737-1747.

6. Kelley, D.E., Mokan, M., Simoneau, J.-A., and Mandarino, L.J. 1993. Interaction between glucose and free fatty acid metabolism in human skeletal muscle. J. Clin. Invest. 92:91-98.

7. Yki-Järvinen, H., Puhakainen, I., and Koivisto, V.A. 1992. Effect of free fatty acids on glucose uptake and nonoxidative glycolysis across human forearm tissues in the basal state and during insulin stimulation. J. Clin. Endocrinol. Metab. 72:1268-1277.

8. Wolfe, B.M., Klein, S., Peters, E.J., Schmidt, B.F., and Wolfe, R.R. 1988. Effect of elevated free fatty acids on glucose oxidation in normal humans. Metab.Clin. Exp. 37:323-329.

9. Bevilacqua, S., et al. 1987. Acute elevation of free fatty acid levels lead to hepatic insulin resistance in obese subjects. Metab. Clin. Exp. 36:502-506.

10. Bevilacqua, S.,et al. 1990. Operation of Randle's cycle in patients with NIDDM. Diabetes. 39:383-389.

11. Yki-Järvinen, H., Puhakainen, I., Saloranta, C., Groop, L., and Taskinen, M.-R. 1991. Demonstration of a novel feedback mechanism between FFA oxidation from intracellular and intravascular sources. Am. J. Physiol. 260:E680-E689.

12. Randle, P.J., Garland, P.B., Hales, C.N., and Newsholme, E.A. 1963. The glucose fatty-acid cycle: its role in insulin sensitivity and the metabolic disturbances of diabetes mellitus. Lancet. i:785-789.

13. Randle, P.J., Garland, P.B., and Hales, C.N. 1965. The glucose fatty acid cycle in obesity and maturity onset diabetes mellitus. Ann. NY Acad. Sci. 131:324-333.

14. Roden, M., et al. 1996. Mechanism of free fatty acid-induced insulin resistance in humans. J. Clin. Invest. 97:2859-2865.

15. Boden, G., et al. 1991. Effects of fat on insulin-stimulated carbohydrate metabolism in normal men. J. Clin. Invest. 88:960-966.

16. Boden, G., Chen, X., Ruiz, J., White, J.V., and Rossetti, L. 1994. Mechanism of fatty acid-induced inhibition of glucose uptake. J. Clin. Invest. 93:2438-2446.

17. Hubert, P., Brunea-Wack, C., Cremel, G., LeMarchand-Brustel, Y., and Staedel, C. 1991. Lipid-induced insulin resistance in cultured hepatoma cells is associated with a decreased insulin receptor tyrosine kinase activity. Cell Regul. 2:65-72.

18. Usui, I., et al. 1997. Fatty acid induced insulin resistance in rat-1 fibroblasts overexpressing human insulin receptors: impaired insulin-stimulated mitogen activated protein kinase activity. Diabetologia. 40:894-901.

19. Svedberg, J., Bjorntorp, P., Smith, U., and Lonnroth, P. 1992. Effect of free fatty acids on insulin receptor binding and tyrosine kinase activity 
in hepatocytes isolated from lean and obese rats. Diabetes. 41:294-298. 20. Gumbiner, B., Mucha, J.F., Lindstrom, J.E., Rekhi, I., and Livingston, J.N 1996. Differential effects of acute hypertriglyceridemia on insulin action and insulin receptor autophosphorylation. Am. J. Physiol. 270:E424-E429.

21. Cline, G.W., Jucker, B.M., Trajanoski, Z., Rennings, A.J.M., and Shulman, G.I. 1998. A novel ${ }^{13} \mathrm{C}$ NMR method to assess intracellular glucose concentration in muscle, in vivo. Am. J. Physiol. 274:E381-E389.

22. Rothman, D.L., Shulman, R.G., and Shulman, G.I. 1992. ${ }^{31} \mathrm{P}$ nuclear magnetic resonance measurements of muscle glucose-6-phosphate. Evidence for reduced insulin-dependent muscle glucose transport or phosphorylation activity in non-insulin-dependent diabetes mellitus. J. Clin. Invest. 89:1069-1075.

23. Shulman, G.I., et al. 1990. Quantitation of muscle glycogen synthesis in normal subjects and subjects with non-insulin-dependent diabetes by ${ }^{13} \mathrm{C}$ nuclear magnetic resonance spectroscopy. N. Engl. J. Med. 322:223-228.

24. Cline, G.W., et al. 1997. Mechanism of impaired insulin stimulated muscle glucose metabolism in subjects with insulin-dependent diabetes mellitus. J. Clin. Invest. 99:2219-2224.

25. Adriany, G., and Gruetter, R. 1997. A half-volume coil for efficient proton decoupling in humans at 4 Tesla. J. Magn. Reson. 125:178-184

26. Shen, J., Rycyna, R.E., and Rothman, D.L. 1997. Improvements on an automated shimming sequence (FASTERMAP). Magn. Reson. Med. 38:834-839.

27. Shen, J. 1996. Use of amplitude and frequency transformations to generate adiabatic pulses of wide bandwidth and low RF power deposition. J. Magn. Reson. 112:131-140.

28. Ruderman, N.B., Kapeller, R., White, M.F., and Cantley, L.C. 1990. Acti- vation of phosphatidylinositol 3-kinase by insulin. Proc. Natl. Acad. Sci. USA. 87:1411-1415.

29. Goodyear, L.J., et al. 1995. Insulin receptor phosphorylation, and phosphatydlinositol 3-kinase activity are decreased in intact muscle strips from obese subjects. J. Clin. Invest. 95:2195-2204.

30. Yki-Jarvinen, H., Puhakainen, I., Saloranta, C., Groop, L., and Taskinen, M.-R. 1991. Demonstration of a novel feedback mechanism between FFA oxidation from intracellular and intravascular sources Am. J. Physiol. 260:E680-E689.

31. Kahn, B.B. 1996. Glucose transport: pivotal step in insulin action. Diabetes. $45: 1644-1654$

32. Kahn, C.R. 1994. Insulin action, diabetogenes, and the cause of type II diabetes. Diabetes. 43:1066-1084.

33. Okada, T., Kawano, Y., Sakakibara, T., Hazeki, O., and Ui, M. 1994. Essential role of phosphatidylinositol 3-kinase in insulin-induced glucose transport and antilipolysis in rat adipocytes: studies with a selective inhibitor wortmannin. J. Biol. Chem. 269:3568-3573.

34. De Fea, K., and Roth, R. 1997. Protein kinase C modulation of insulin receptor substrate- 1 tyrosine phosphorylation requires serine 612 . Biochemistry. 36:12939-12947.

35. Björnholm, M., Kawano, Y., Lehtihet, M., and Zierath, J.R. 1997. Insulin receptor substrate-1 phosphorylation and phosphatidylinositol 3-kinase activity in skeletal muscle from NIDDM subjects after in vivo insulin stimulation. Diabetes. 46:524-527.

36. Anai, M., et al. 1998. Altered expression levels and impaired steps in the pathway to phosphatidylinositol 3-kinase activation via insulin receptor substrates 1 and 2 in Zucker fatty rats. Diabetes. 47:13-23.

37. Kasanicki, M.A., and P.F. Pilch. 1990. Regulation of glucose-transporter function Diabetes Care. 13:219-227. 